\title{
Achieving competitive advantage through effective communication in a global environment
}

\author{
Uche Nwabueze \\ Maritime Administration Department, Texas A\&M University at \\ Galveston, \\ United States of America \\ nwabuezen@tamug.edu \\ Joan Mileski \\ Maritime Administration Department, Texas A\&M University at \\ Galveston, \\ Unites States of America \\ mileskij@tamug.edu
}

Abstract. Considerable research has been conducted to analyze the effects of elements such as information technology, efficiency, and innovation on the performance of a company (Bhatt \& Grover, 2005; Bowonder et al, 2010; Ogrean et al, 2009; Piccoli \& Ives, 2005). However, company success is dependent on effective communication particularly in a multicultural and competitive global environment yet the types of effective communication that impact competitiveness have not been well explored. Although companies are aware of the importance of communication, far less attention is paid to promoting the use of effective communication within and outside the organization as compared to other factors. The Macondo oil spill crisis in the Gulf of Mexico provides a topical case study of how global companies can suffer performance losses due to ineffective communication. Traditional views of organizational competitive advantage have failed to directly address the importance of communication as a differentiator. This paper addresses the importance of effective communication in building and maintaining performance success (Tucker et al 1996) and explores three key types of effective communication in maintaining success through competitive advantage. These three types include the right combination of "soft" and "hard" information gathering, superior interpersonal communication and the appropriate use of information and communication technologies. We use the Macondo case study as a venue to test the successes and failures of communication on performance We find where there is a lack of effective communication an organization's global competitive ability is severely impaired. Further, we address how communication impacts the other elements that contribute to competitive advantage such as efficiency, responsive public

\author{
Received: \\ August, 2017 \\ 1st Revision: \\ October, 2017 \\ Accepted: \\ December, 2017 \\ DOI: \\ 10.14254/2071- \\ $8330.2018 / 11-1 / 4$
}


relations and innovation. We use the findings to present strategies and recommendations to help an organization use effective communication to achieve superior customer satisfaction, encourage innovation, motivate employees, and respond to crises more effectively.

Keywords: Communication and firm performance, metrics of communication, nature and form of communication.

JEL Classification: M16

\section{INTRODUCTION OF COMMUNICATION WITHIN AN ORGANIZATION}

Some studies have focused on the importance of effective communication as a means to achieve and retain competitive advantage (Tucker et al 1996). In today's global business environment, effective internal and external communication has a significant impact on the success of the organization (Chiou et al., 2004). This paper explores recent research to identify some of the building blocks such as efficiency, innovation, and customer response that enable a company to gain advantage over its competitors. The influences of communication on the factors that govern competitive advantage are analyzed. The paper demonstrates that effective communication is the common bond and unifying thread linking all the relevant factors to achieve and retain competitive advantage in a multicultural environment. Conversely, it also shows that ineffective communication can result in erosion of customer confidence and a subsequent deterioration in the organization's ability to compete effectively.

Any form of communication consists of two phases - the transmission and the feedback (Tarokh et al, 1998). In the transmission phase, information is shared between two or more individuals (Onnela et al, 2006). Feedback, on the other hand, is the response of the audience (Armson et al, 1997). Giving the audience a chance to provide feedback ensures a common understanding and an open communication environment. Communication can either be verbal, nonverbal, or visual (Poyatos, 1992). Communication that is either written or spoken is verbal communication. On the other hand, communication using body language such as posture, facial expression, and eye contact and communication using objects such as clothing, accessories, and hairstyles are all forms of non-verbal communication (Dumbrava \& Koronka, 2009; Subapriya, 2009).

Visual communication, as the name suggests, is communication through visual aid. It is the exchange of ideas and information in a form that is visible to the human eye (Knox, 2007). It is primarily associated with two dimensional images such as signs, typography, drawing, graphic design, illustration, and electronic resources. Communication can also be classified based on the number of people involved in the process (Frey et al, 1991). Communication with oneself is called intrapersonal communication; whereas, interpersonal communication is the interaction between different people (Jemmer, 2009).

Organizational communication can be upward, downward, or lateral in nature (Garnett et al, 2008). Upward communication is the flow of information from subordinates to superiors or from employees to management. This is essential to communicate ideas, drive innovation, and obtain valuable feedback (cite?). According to Tepper et al (2007), efficient upward communication, using direct tactics such as openly discussing relationship issues, will enable companies to mitigate psychological distress of employees due to abusive supervisors. Information flowing from the top of the organizational management hierarchy, telling people in the organization about the company mission, a course of action to achieve those goals, and enforcing policies is a part of downward communication. Lateral 
communication involves people within the same or similar rank in an organization (Garnett et al., 2008). This form of communication involves coordinating information, accomplishing tasks, solving problems, building goodwill, and collaborating to achieve company goals (Fig. 1).

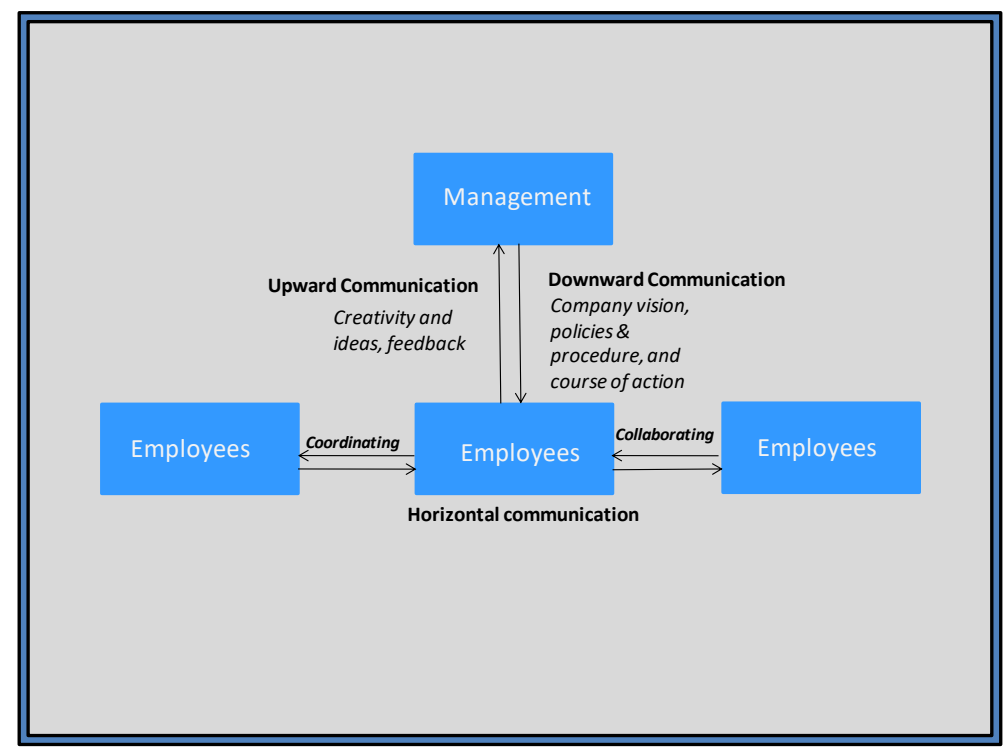

Figure 1. Communication within an organization.

\section{LITERATURE REVIEW}

\subsection{Factors that govern competitive advantage}

Competitive advantage is the ability of one organization to outperform others because it produces desired goods or services more efficiently and effectively than its competitors. As indicated by Ogrean et al, (2009), some of the important elements required for a global competitive advantage are efficiency, innovation, customer response, and public relations. The following sections describe how effective communication affects these crucial drivers to achieve competitive advantage.

\subsection{Effective communication}

Effective communication in global organizations includes the right combination of "soft" and "hard" information gathering, superior interpersonal communication and the appropriate use of information and communication technologies (Uchida, 2011).

\subsection{1 "Soft" and "hard" information gathering}

Effective communication includes the effective use of information both "soft" or "hard" information gathering. For example, relationship lending, the most common techniques for lending to small firms, is based on the "soft" information which is accessible by keeping a close relationship with the client. (Uchida, 2011) Alternatively, there exist transaction-based lending techniques, those are mainly based on the "hard" information about the businesses (Uchida, 2011). An example of transaction-based lending include financial statements based lending, asset based lending and credit scoring (Petersen \& Rajan, 2002). Research dealing with the soft information generation and bank lending efficiency argues 
that the soft information collection and careful examination of the information can increase the lending efficiency of the bank that can positively affect the small business access to credit (D'Aurizio et al., 2015). On the other hand, empirical results show that commercial banks can improve the credit rating model by including the relationship lending qualitative (soft) information of the borrower in the rating process, and that focus only on the hard financial information can be misleading (Dolezal et al., 2015). Therefore, a combination of soft and hard information gathering can provide improved company performance.

\subsubsection{Superior interpersonal communication}

Sharing knowledge about day-to-day operations within an organization is a great way to promote interpersonal relations. Information or knowledge sharing can aid in the alignment of corporate goals, vision and values, and create awareness about competition within an organization (McNeish \& Mann, 2010). Knowledge sharing can assist in knowledge transfer, improve group processes, and therefore, lead to efficient decision making. Better decisions, in turn, lead to success that can be measured in terms of increased sales, margins, and reduced operating costs within an organization.

Additionally, communication can increase trust and improve relationships among organizational members that consequently results in individuals focusing on the long-term benefits of the relationship rather than short-term transient benefits. Furthermore, there is evidence that social network, interaction, and communication have important effects on team performance and viability (Balkundi \& Harrison, 2006). Teams that engage in social networking attain their goals more frequently and remain as a group for longer periods of time.

For practicing managers, communicating with employees, especially in difficult situations, can be a challenge. On the one hand, managers have to ensure that employees complete the task in hand, but, on the other hand, managers who are excessively task oriented and less focused on interpersonal communication risk offending employees or be accused of the dreaded "micro managing." According to Campbell (2006), managers cannot always deliver good news to employees. Instead, managers often face circumstances where they must issue orders to get the task completed. Additionally, managers may have to provide negative performance feedback to employees. Any of these interactions when handled inappropriately has the potential to damage the superior-subordinate relationship. Campbell advocates that managers think (T) and interact (I) like (L) a leader (L). According to this TILL model, the path to successful employee relationship lies in the tone and the choice of words the manager uses to communicate.

\subsubsection{Appropriate use of information and communication technologies}

Computers and informational technology are now as much about communication as they are about computation. Most researchers refer to informational and communication technologies as a term that includes people, software applications, systems, and networks (Tilley, 2000). Aldhmour and Shannak (2009) define ICT to "include all the technology that facilitates the processing and, transfer, and exchange of information and communication services" (p. 303). The authors indicate that there is a positive relationship between the use of ICT and a competitive advantage. The implementation of ICT has a beneficial effect on product quality and organizational performance. 


\subsection{The impact of communication on competitive advantage drivers}

As noted above, Ogrean et al. (2009), some of the important elements required for a global competitive advantage are efficiency, innovation, customer response, and public relations. We describe the impact of the three primary effective communication elements on the competitive advantage drivers.

\subsubsection{Increasing efficiency}

Three primary means to improve efficiency utilizing communication include superior interpersonal communication, effective use of information and the effective use of communication technologies (ICT) (Uchida, 2011). The efficiency of an organization is increased by utilizing a minimal quantity of resources to produce quality products for customers. This would include the right mix of "soft" and "hard" information gathering. According to Barney (1991), a resource that contributes towards improving an organization's efficiency and effectiveness in satisfying customer needs should be identified as a source of competitive advantage (Le Roux and Oosthuizen, 2010). Good organizational communication, particularly interpersonal communication, is, in turn, vital to efficiently utilizing human and raw material resources. Further, ICT makes the availability of information pervasive, thereby decreasing uncertainty in a business environment and improving efficiency. ICT also allows companies to understand the needs of the customer and gain insights about their competitors. This information, in turn, allows companies to build their strategy, communicate these strategies with people within the organization, implement action roadmaps, and track success and performance.

Organizational growth in countries such as China can be attributed to ICT. According to the Lam and Ho Kin (2010), ICT in corporate education and training helps create self-managed teams by empowering the employees, thereby increasing productivity. It increases the resources and support available to workers, thereby opening up new avenues to professional development. Bulearca and Bulearca (2009) endorse the viability of ICT in a global competitive market. Their research indicates that the use of ICT is associated with higher contributions or value added per worker as shown in Fig. 2.

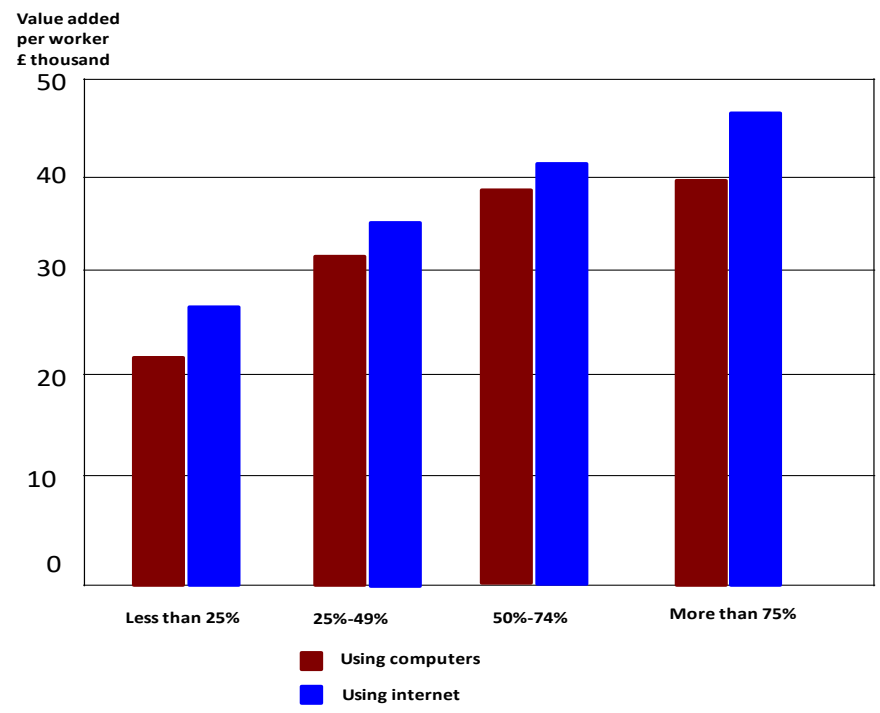

Figure 2. Information and Communication Technologies (ICT) are associated with higher value added per worker

Adapted from "Internet and Interactive Websites: Cornerstones of Competitive Advantage in the Virtual Economy," by M. Bulearca and S. Bulearca, 2009, Global Business \& Management Research, 1, p. 49. 


\subsubsection{Enabling innovation}

Communication or its lack can either drive or stall innovative and creative solutions within an organization. Research conducted by Gilley, Dixon, and Gilley (2008) examine the skills and behavior of leadership and management with respect to change and innovation. In particular, they investigate whether the leaders were able to effectively implement change within their organizations by asking employees to evaluate how frequently leaders coached, rewarded, communicated, motivated, and encouraged teamwork and collaboration among employees. The results of the study confirm that the inability to communicate and motivate were the primary causes of organizational failure. The research also shows that the ability to communicate interpersonally appropriately and motivate others influences a leader's ability to effectively implement change and drive innovation. In order to be viable in a highly competitive environment, organizations should be able to anticipate, adapt, and execute change successfully.

Denning (2005) argues that only truly efficient leadership communication can motivate employees and inspire organizations. According to Denning, innovation requires leadership to communicate the benefits of embracing a radically different future. Change from status quo requires leaders to communicate a sense of urgency, thereby motivating and inspiring individuals to act (Kotter, 2008). According to a study conducted by Birdi (2005), poor leadership support, lack of encouragement, and an inadequate work environment limit creativity and innovation. This study involving highly creative technical professionals shows that good interpersonal communication skill is essential for fostering creativity amongst technical visionaries. Managers, who communicated, encouraged employee feedback, listened, and showed interest and appreciation are able to motivate their employees to come up with important innovations (Hebda, Vojak, Griffin, \& Price, 2007) particularly if information gathered is the right mix of "soft" and "hard" data

In addition, implementation of ICT drives innovation, helping organizations improve the quality of existing products and invent new products to satisfy consumer needs. ICT also allows companies to control the production process by using systems for entering orders, determining production capacity, and tracking inventory (Aldhmour \& Shannak, 2009). All of these primary effective communication elements enhance innovation.

\subsubsection{Improving customer response}

Increased competition results in an increase in the number of choices available to customers. Even when products are satisfactory customers may shop around either to find a better bargain or sometimes merely for change. Raman, Wittmann, and Rauseo (2006) identify customer relationship management as a valuable tool to increase sales effectiveness, and therefore, consider it to be an advantage-producing resource. Customer relationship management through direct superior interpersonal communication in call center and web site communication, in gathering good "soft" and "hard" data on customers, and in the appropriate use of ICT through wireless communication enable organizations to develop meaningful relationships with their clients (Dumitrescu \& Fuciu, 2009). According to Wood (2009), a prerequisite for attracting and retaining satisfied customers, a measure of global competitive advantage, is communication.

\subsubsection{Enhancing public relations}

An organization's reputation, profitability, and even its continued existence can depend on the degree to which the public supports its goals and policies. A good reputation, in turn, can enhance competitive advantage (Fombrun, 2015). Public relations specialists, also referred to as communications 
specialists, serve as advocates for an organization seeking to build and maintain positive relationships with the public. Public relations specialists handle organizational functions such as media, community, consumer relations, political campaigns, and conflict mediation. Public relations specialists must understand the attitudes and concerns of the community, consumer, employee, and public interest groups to establish and maintain cooperative relationships (Newsom et al, 2012). Therefore, it would be prudent for the public relations specialist to engage in superior interpersonal communication and provide the stakeholders with the right mix of "soft" and "hard" information through the appropriate use of ICT.

According to Payne (2006), the success of an organization depends on developing and maintaining its reputation with important stakeholders including customers. Further, corporate reputation depends on various factors including intangibles such as strategic management, degree of consumer confidence, brand loyalty, organizational communication and behavior, and public relations (Payne, 2006). An organization's reputation primarily depends on its character and its ability to effectively communicate with all stakeholders, keeping them informed at all times. It is important for an organization to ensure that communication is regular and not merely intermittent responses generated only during crises (Gibson, Gonzales, \& Castanon, 2006). Organizations can enhance public relations and manage their reputation by demonstrating continuous corporate responsibility through actions, social and ethical behavior, and efficient communication with the public. $\mathrm{Ki}$ and Hon (2009) indicate that in an organization-public relationship "openness is an important indicator of relationship quality outcomes" (Payne, 2006 p. 7 ). One of the critical ways to ensure regular and efficient and effective communication is through the use of ICT.

\subsection{Challenges to effective communication}

The style of communication varies between different cultures and within cultures themselves. Learning to respect differences and working together towards a unified goal can be a challenge. Another challenge most companies face is communication during crises. This can be addressed if a company makes effective communication an integral part of their contingency planning (Lentzos and Rose, 2009). The following sections describe the principal challenges to effective communication of superior interpersonal communication, information gathering, and appropriate use of communication technology (ICT), particularly those encountered in multicultural settings and those related to uncertainties that manifest themselves during crises.

\subsubsection{Multicultural environment}

In an increasingly globalized and multicultural environment, the ability to effectively communicate across cultures is not only important but also challenging. Today, managers and professionals at all levels of an organization interact with people from different cultural backgrounds. Global virtual teams that enable companies to become globally competitive are common in organizations (Jarvenpaa and Leidner, 1998). As a result, it is important for an organization to recognize the importance of cultural differences and the need to establish effective communication channels to interact with people from other cultures.

According to Liu, Chua, and Stahl (2010), the quality of communication among people of different cultures is an important element in determining the outcome of such interactions. Their study proposes that there are three dimensions to the quality of communication experience (QCE) - clarity, responsiveness, and comfort. Findings from intercultural and same cultural negotiations showed that clarity, responsiveness, and comfort were lower in interactions between people of different culture, thus showing that superior interpersonal communication leading to competitive advantage is a challenge. The 
study also found that the amount of time and energy needed for communication, as well as the likelihood of miscommunication, increase tremendously as cultural differences increase. Based on their findings the authors propose that managers and negotiators need to strive for clarity in their communication through active listening, clarifying terms and meanings, understanding the situation, and expressing their own ideas clearly verifying that information gathering should be a mix of "soft" and "hard" data. In addition, Liu et al. (2010) emphasize the importance of being responsive to overtures by reciprocating and being cognizant of the other party's behavioral patterns, values, norms, and expectations. Finally, according to the authors, it is important to put the other party at ease and make them feel comfortable and safe.

It is imperative for the communicator to be conscious of the content, clarity, responsiveness and comfort of the opposite party. Strategies for managing effective communication through QCE can also be used in a wide range of organizational contexts including communication with multicultural team members, forming alliances with international companies, worldwide telemarketing and customer communication, negotiations, and mergers and acquisitions. Noting that the appropriate use of ICT can go a long way to enhance cross cultural communication.

\subsubsection{Crisis management}

Recent corporate crises such as the Macondo oil spill in the Gulf of Mexico have shed new light on how a lack of adequate communication can tarnish the image of a corporation and diminish competitive advantage. Manoj and Baker (2007) indicate that a primary challenge underlying all crisis responses is communication with all stakeholders. Their research has revealed that there are three categories of communicational challenges: technological, sociological, and organizational. These areas are important to develop and maintain healthy and effective disaster communication systems. In most disasters the primary technological challenge is deployment of communication for disaster management workers and first responders.

The social challenges that arise with communication during such crises must also be considered. Since it becomes difficult to identify who to trust in the chaotic and unfamiliar situations such as a crises, sharing and dissemination of information becomes both critical and often problematic. Superior interpersonal communication skills can enhance trust in the information provided. Threats posed by security issues frequently become an area of concern. An additional challenge is the unpredictability of emotions among victims. Anxiety, anger, fear, and other emotions are all exacerbated by absence or inadequate information (Manoj \& Barker, 2007). In such situations organizations must realize the importance of frequent communication and updates. Here the use of ICT can assist to overcome uncertainty to the stakeholders.

Organizations where people are accustomed to hierarchical decision making typically find themselves working in a flatter, more dynamic and ad-hoc organization that emerges during post-disaster relief effort (Tierney, et. Al, 2001). Therefore, during such crises the challenge becomes how to effectively communicate with both the employees of the organization and the general public. Gathering of the right mix of data provides more flexibility to handle contingencies. Prior contingency planning, including scenario enactments and dry runs, and formal risk management can be of enormous assistance during a crisis (Tierney et, al, 2001). Advance planning should include creation of crisis communication teams responsible for communicating with employees, the media, and the public. Effective communication during such crises could eliminate the dissemination of erroneous information, alleviate fear, offer guidance, and show the people involved that the organization cares. The following case illustrates how a 
loss of consumer confidence and hence reduced competitive advantage can be attributed to ineffective communication.

\section{METHODOLOGY AND CASE}

\subsection{Methodology}

This paper uses an explanatory case study approach to provide an explanation for a set of events or outcomes and to indicate how such an explanation may apply to other situations (Yin, 1989). We explore why our explanation of the elements of effective communication were or were not present and how that impacted the competitive advantage of the organization. Further, we contend that this explanation is applicable to other situations.

\subsection{Case description}

The recent BP (Macondo) oil spill in the Gulf of Mexico is used as the explanatory case study. The facts of the case are as follows:

As the expanding oil slick threatened coastal marshlands, distressed wildlife, and affected the livelihood of numerous fishermen, British Petroleum (BP) faced perhaps the biggest public relations challenge an oil company experienced in the United States since the Alaskan Exxon Valdez disaster in 1989. The public relations challenge was caused by a series of bad business decisions. So effective communications during and after the disaster could have potentially mitigated some of the damage to competitive advantage held by BP due to the spill disaster.

Prior to the spill event, the decisions and how they were communicated BP made over the course of the well drilling project rendered it vulnerable to the blowout that unleashed the huge oil spill. BP struggled for over 87 days to contain the spill. According to Snow (2010), information provided by BP PLC to the U.S. House Energy and Commerce Committee on May 12, 2010 concerning the rig accident which caused the spill in the Gulf of Mexico on April 20, 2010 confirmed many of the concerns and issues that were raised by the panel. The information supplied by BP identified several new warning signs that were ignored or not communicated before the rig exploded, killing $11 \mathrm{crew}$ members. Key questions existed about whether proper procedures were followed for critical activities. According to Casselman and Gold (2010), BP failed to follow safety procedures and eliminated critical steps involving drilling fluid that is designed to detect gas and remove it before it poses a threat. In addition, despite a warning and information supplied by the cement contractor, Halliburton Co, BP also skipped a quality test of cement around the pipe, which was supposed to act as a buffer against gas. Once the gas began rising, BP's decisions and implementation choices made the gas easier to rise to the surface. Additionally, the BP manager overseeing the well tests had little experience in deep-water drilling. He told investigators that he was on the rig to learn about deep water drilling.

Some of the choices made by BP were made to minimize costly delays. There was pressure to wrap up the project quickly. For instance, a subcontractor who cleaned tanks was made to clean two tanks instead of the usual one. On the morning of April 20, 2010 there was a disagreement between Transocean workers and BP's top manager regarding implementation of safety procedures. Transocean workers disagreed with a decision by BP's top manager about when and how to remove the drilling mud and replace it with lighter seawater. Transocean workers felt that the decision was not made on all information. Transocean reluctantly agreed to follow the procedure outlined by BP as the interpersonal relationship between decision maker in BP and the decision maker in Transocean was icy. The heavy 
drilling mud and the blowout preventer were the two critical safety devices that kept the explosive mixture of oil and gas from reaching the rig. Following BP's instruction, Transocean workers started replacing the mud with seawater. Unaware that the seawater and mud was beginning to head up the pipe, the crew continued with their work. Later that evening, the crew witnessed mud shooting out from the derrick. Frantic calls for information on what to do were made to BP while Transocean tried unsuccessfully to tame the well as the ICT failed during the crisis. According to several witnesses, the workers rushed to push the emergency button to activate the blowout preventer and detach the rig from the well. The damage had already been done and it was too late to rectify it. The gas flowing out ignited and an explosion rocked the rig taking the lives of 11 oil rig workers and eventually sinking it (Casselman \& Gold, 2010).

After the blowout, communication with the public and the employees was made through the media. Further, the then CEO, Tony Hayward, commented during the clean-up crisis that he "wanted his life back" (Fabian, 2010). He subsequently apologized publically for his comment and poor communication.

\section{EMPIRICAL RESULTS}

The recent Macondo oil spill in the Gulf of Mexico reinforced the necessity of effective communication. British Petroleum (BP) faced perhaps the largest crisis in its history threatening their competitive advantage. According to Snow (2010), information provided by BP PLC to the U.S. House Energy and Commerce Committee on May 12, 2010 concerning the rig accident in the Gulf of Mexico on April 20, 2010 showed that no element of effective communication was used by BP prior to, during and after the crisis.

First, superior interpersonal communication was not present. Communication on proper procedures for critical activities was absent. According to Casselman and Gold (2010), BP managers did not follow nor communicate the need to follow safety procedures. In addition, interpersonal communication failed because a warning from the cement contractor, Halliburton Co, was not heeded. Second, as events progressed and warnings such as gas rising in an inappropriate place, BP's further did not gather the appropriate mix of data on which to make decisions. Finally, the BP manager overseeing the well tests did not rely on information provided by various ICT.

The reasons and motivations prompting the ineffective communications are many but the critical conclusion of the impact on BP's competitive advantage particularly in the United States is clear. Efficiency is lost by the 87 days of clean-up and recovery. Innovation is setback by the $\$ 20$ billion in fines and penalties. Their public relations were a disaster evidenced by BP's withdrawal of operations in the US including sale of a significant refinery in Texas City, Texas (De La Merced, 2012).

The Gulf of Mexico oil spill crisis can be attributed, in part, to the failure of effective communication between Transocean and BP that resulted in disastrous choices. Could effective communication have prevented this hazard? Could post event communication salvaged BP's competitive advantage?

According to BP, it does have a public policy in place that stresses the importance of safety. However, the inability to ensure that safety took precedence over other considerations and constraints can be attributed to a failure of effective communication as noted above. Ideally, communications among members of an effective group should focus on proper procedure and ensure that discrepancies are resolved amicably. In addition, the disagreement about procedures being followed between Transocean and BP also shows ineffective communication. This is not only common within an organization but can be highlighted where organizations employ subcontractors. Despite being the rig owner, and possessing 
specialized knowledge, Transocean deferred too much of the decision making authority to BP and failed to convincingly communicate appropriate safety recommendations.

Further, BP was ineffective communication during crisis management following the incident. They failed to put in place a coherent system of procedures and communication policies during the time it took to cap the well. They did not control communication by employees including the CEO with the public at large.

Companies typically face technological, sociological, and organizational challenges during crises (Manoj \& Baker, 2007). BP should have been able to foresee the technical challenges during a crisis and put in place a solution for recovery. Even more damaging to BP's public image was the lack of communication and slow response, giving the appearance of a lack of concern which provided the sociological challenge. This, in turn, resulted in a loss of consumer confidence as indicated by the fall in stock prices. BP's stock price on the New York Stock Exchange fell from $\$ 60.48 /$ share closing price on April 20, hours before the well blew out, to its current value of $\$ 36.00 /$ share. Major credit rating services such as Fitch Rating Services and Moody's Investors Services have downgraded BP's long-term credit ratings and have warned that further decline is possible (Snow, 2010).

Finally, the organizational challenge that BP continues to face is that of communicating with the victims and its own employees and shareholders. Having already failed at the technological and sociological challenges of effective communication, BP also stands to fail at the organizational level if it does not see the importance of such communication. Frequent communication is especially important in alleviating the anxiety, fear, and anger typically faced by the members of the organization under such circumstances. In this case, ineffective communications led to critical errors in choice of procedure, a damaged public image, and poor crisis management. BP is now a company that has lost a great deal of its competitive advantage due to ineffective communication and is worth 75 billion less after the incident. As BP tries to recover and move forward, effective communication will again be a key differentiator in rebuilding its credibility and regaining its competitive advantage.

\subsection{Communication strategies to build and maintain competitive advantage}

In building a competitive advantage, companies need to recognize that information is power; therefore, broadening access to information and increasing transparency will influence the productivity, viability, and long-term success of a company (Tucker et al, 1973). We have focused on increasing efficiency, enabling innovation and enhancing public relations (corporate image). Figure 3 summarizes these and some additional key facets to achieving a competitive advantage such as customer satisfaction, supply chain synergy, and social responsibility shown in the innermost circle. Key stakeholders such as employees, customers, suppliers, partners, and the general public are shown in the outermost circle. The communication strategies that stakeholders can employ to achieve greater competitive advantage are shown in the middle circle. 


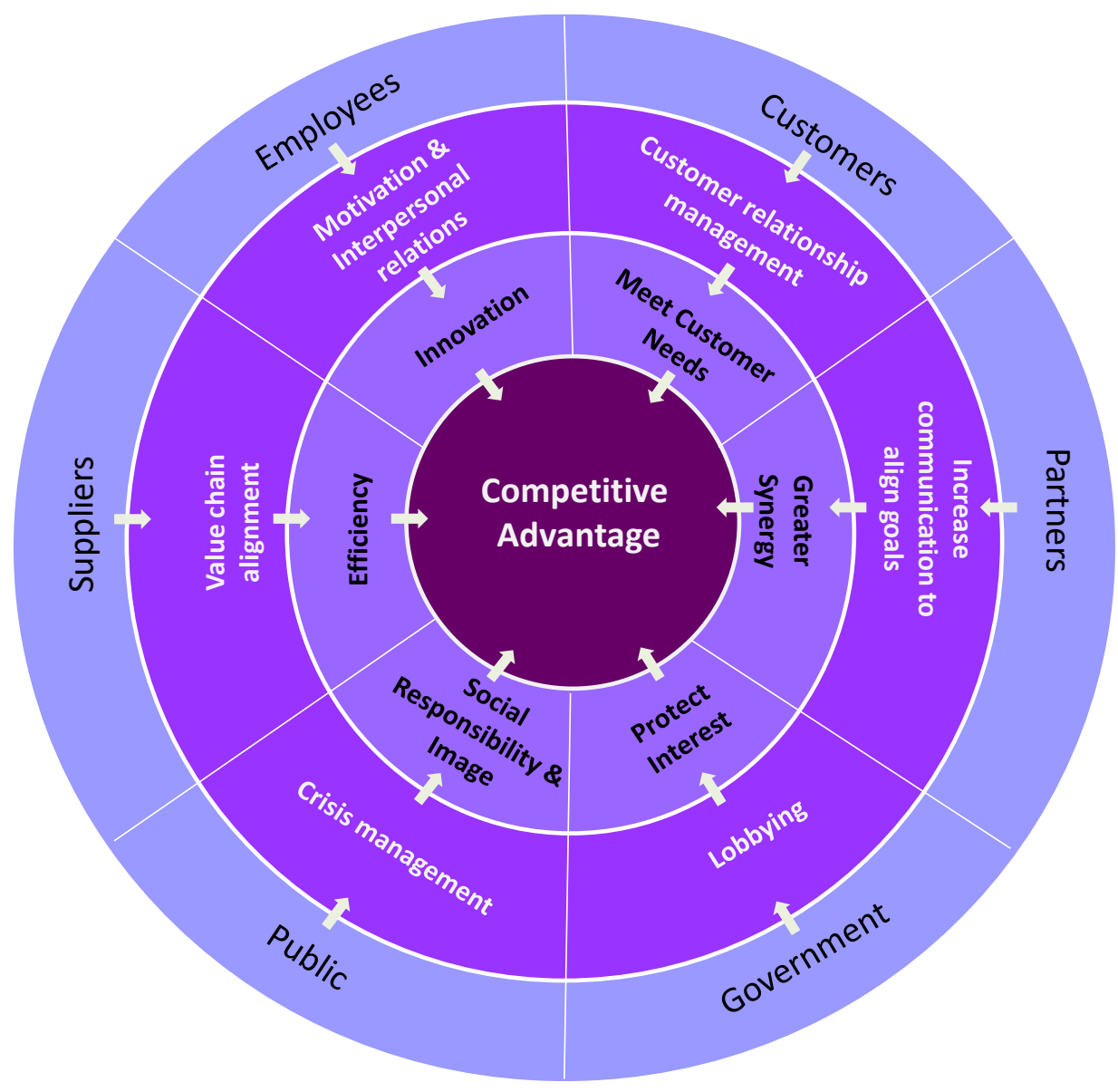

Figure 3. Communication and competitive advantage

\subsubsection{Emphasize customer relationship management}

Organizations should emphasize the importance of managing relationships, building consumer confidence and keeping the public informed about important corporate decisions. A company that gathers the right mix of information by soliciting the opinions of its customers, suggestions from suppliers, and insights of its independent contractors in the co-creation of new products and the improvement of existing products is more likely to succeed than one that works in isolation (Lewis, 1999). This is the fundamental process where effective communication will make a difference. Companies that value the feedback of their customers and incorporate their opinions in design, testing, marketing, and after sales process obtain better insights into the needs of the customer. This can cut costs involved in market research, help speed up the development cycle, and increase customer loyalty.

Sales and marketing departments should be trained to engage customers and encourage them to provide valuable feedback. Additionally, it is important to collect customer details and order histories, create databases to provide company-wide access to information such as customer preferences, and identify new and cross selling opportunities. 


\subsubsection{Build interpersonal relations}

Another step to build competitive advantage is to engage and motivate employees. Sethi and Seth (2009) compare communication to the circulatory system calling it "an inseparable, essential, and continuous process" (p. 32). Barriers to effective interpersonal communication can be overcome by structuring language to be clear and uncomplicated, controlling emotions during discussions, and articulating in a neutral manner thereby encouraging mutual understanding. According to the authors, people often hear the conversation but do not listen to what is being communicated. Active listening skills help managers gain the confidence of their employees. Employees, in turn, are more likely to be receptive to the manager's message. In addition, encouraging employee feedback is also essential for the success of an organization. Feedback keeps managers informed about the strengths and weakness of the organization, informs them about how motivated and satisfied the employees are with their current jobs, and allows them to improve upon their own weaknesses.

It is equally important to assure employees that their suggestions will be taken into consideration. Research shows that a 360-degree feedback system encourages change and innovation (Mamatoglu, 2008). All managers participating in the study receive feedback about their competencies and behavior. The study shows that leaders improved their behavior based upon proper feedback. They, in turn, become a role model for employees, setting an expectation of what is considered normal behavior within the organization. Studies like these demonstrate that communication should not be dominated by hierarchy. Organizations that promote communication and an open door policy are more likely to attract and retain good talent and encourage innovation.

\subsubsection{Manage multicultural interactions}

Cultural sensitization seminars and communication workshops that emphasize the concept of QCE (quality communication experience) should also be an integral part of corporate communication training. This training equips managers with the skills required to manage diverse team members, clients, partners, and vendors from different parts of the world, thereby increasing the competitive advantage of the organization (Chong, 2007).

\subsubsection{Embrace technology}

Companies that promote a truly open, flexible, and organic culture fueled by communication and ICT empower employees who create norms that emphasize creativity, effort, and innovation. Companies where employees are encouraged to train on new information and communication technologies are more likely to be productive, thereby increasing efficiency by controlling the use of human and other resources. Furthermore, companies that take advantage of social networks such as Twitter, and Facebook are more likely to reach a broader audience than companies that are more conservative with their communication choices.

\subsubsection{Increase synergies with suppliers and partners}

Supply chain execution begins at the point a demand is created by the customer and is judged by the efficiency with which that demand is fulfilled (Beamon, 1999). Efficient communication is necessary to ensure value chain alignment and increased synergies among companies, suppliers, distributors, and customers (Flynn et al, 2010). ICT makes it possible for companies to communicate and collaborate with suppliers and distributors to reduce costs and maintain high levels of customer service. The increasing 
interdependence of companies implies that mutual long-term success depends on the entire supply chain and its ability to deliver products quickly, reliably, and economically to all stakeholders including customers (Duchessi \& Chengalur-Smith, 2008).

\subsubsection{Plan for crisis management}

Finally, putting in place a superior communication plan for crisis management will help companies maintain their image, and hence, their competitive advantage even under adverse conditions. Further, the plan must foresee implementation challenges that occur during a crisis. Efficient crisis management will indicate that the company is accountable to all stakeholders

\section{CONCLUSION}

Companies have traditionally focused their time, money, and energy on factors other than communication to promote and enhance their viability and compete in a global market place. Although communication is a strong and an economical tool to implement, accessible to all, organizations have not embraced it with the same enthusiasm as they have other factors. Companies that realize that communication is integral to their strategic success will not only gain a competitive edge but also retain it despite adverse conditions. Furthermore, communication is the distinguishing factor to satisfy customer needs, engage and motivate employees, drive innovation, improve efficiency, display social responsibility during crises, and protect the organization's interests from adverse rules and regulations.

In order to exceed the expectations of customers and not merely meet them, companies should emphasize communication to identify consumer needs and obtain feedback on existing and potential new products. In addition, firms should create a truly open and interactive organizational culture, promote transparency, emphasize active listening skills, and organize cultural sensitization workshops. Problems should be addressed without concern to hierarchy or barriers. Employees that provide exit interviews that may help identify communication problems within an organization should be assured of their privacy and anonymity. Also, companies should solicit feedback from suppliers and partners to synchronize the entire value chain, thereby increasing efficiency. Since crises by their very nature can occur at any time it is vital to have the right communication among people, processes, and systems in order to respond effectively. Finally, organizational interests can be protected against adverse legislation or regulation through effective communication.

\section{REFERENCES}

Aldhmour, F., \& Shannak, R. (2009). The effective utilization of information and communication technology and its impact on competitive advantage. European Journal of Scientific Research, 29(3), 302314.

Armson, J., Foote, S., Witt, C., Kalinowski, J., \& Stuart, A. (1997). Effect of frequency altered feedback and audience size on stuttering. European Journal of Disorders of Communication, 32(3), 359-366.

Balkundi, P., \& Harrison, D. A. (2006). Ties, leaders, and time in teams: Strong inference about network structure's effects on team viability and performance. Academy of Management, 49(1), 49-68.

Bhatt, G., \& Grover, V. (2005). Types of information technology capabilities and their role in competitive advantage: An empirical study. Journal of Management Information Systems, 22(2), 253-277.

Birdi, K. S. (2005). No idea? Evaluating the effectiveness of creativity training. Journal of European Industrial Training, 29(2), 102-111. 
Bowonder, B., Dambal, A., Kumar, S., \& Shirodkar, A. (2010). Innovation strategies for creating competitive advantage. Research Technology Management, 53(3), 19.

Bulearca, M., \& Bulearca, S. (2009). Internet and interactive websites: Cornerstones of competitive advantage in the virtual economy. Global Business \& Management Research, 1(3/4), 44-56.

Campbell, K. S. (2006). Thinking and interacting like a leader: The TILL system for effective interpersonal communication. Chicago, IL: Parlay Press.

Casselman, B., \& Gold, R. (2010). BP decisions set stage for disaster. The Wall Street Journal. Retrieved from http:/ / online.wsj.com/article/SB10001424052748704026204575266560930780190.html

Chong, M. (2007). The role of internal communication and training in infusing corporate values and delivering brand promise: Singapore Airlines' experience. Corporate Reputation Review, 10(3), 201-212.

Denning, S. (2005). Transformational innovation. Strategy \& Leadership, 33(3), 11-16.

Duchessi, P., \& Chengalur-Smith, I. (2008). Enhancing business performance: Via vendor managed inventory applications. Communications of the ACM, 51(12), 121-127.

Dumbrava, G., \& Koronka, A. (2009). "Actions speak louder than words"- Body language in business communication. Annals of the University of Petrosani Economics, 9(3), 249-254.

Dumitrescu, L., \& Fuciu, M. (2009). Customer relationship management - A new method of targeting the $21^{\text {st }}$ century consumers. Annals of the University of Petrosani Economics, 9(3), 255-260.

Eicher-Catt, D., \& Catt, I. (2008). What can it mean to say that communication is "effective" (and for whom) in post modernity? Atlantic Journal of Communication, 16(3/4), 119-121.

Fabian, Jordan (2010) BP CEO apologizes for saying "I want my life back," The Hill, 6/2.10.

Flynn, B. B., Huo, B., \& Zhao, X. (2010). The impact of supply chain integration on performance: A contingency and configuration approach. Journal of operations management, 28(1), 58-71.

Frey, L., Botan, C. H., \& Kreps, G. (2000). Investigating communication. NY: Allyn \& Bacon.

Garnett, J., Marlowe, J., \& Pandey, S. (2008). Penetrating the performance predicament: Communication as a mediator or moderator of organizational culture's impact on public organizational performance. Public Administration Review, 68(2), 266-281.

Gibson, D., Gonzales, J., \& Castanon, J. (2006). The importance of reputation and the role of public relations. Public Relations Quarterly, 51(3), 15-18.

Gilley, A., Dixon, P., \& Gilley, J. (2008). Characteristics of leadership effectiveness: Implementing change and driving innovation in organizations. Human Resource Development Quarterly, 19(2), 153-169.

Hebda, J. M., Vojak, B. A., Griffin, A., \& Price, R. L. (2007, August). Motivating technical visionaries in large American companies. IEEE Transactions on Engineering Management, 54(3), 433-444.

Jemmer, P. (2009). Intrapersonal communication: The hidden language. European Journal of Clinical Hypnosis, 9(1), 37-49.

Jarvenpaa, S. L., \& Leidner, D. E. (1998). Communication and trust in global virtual teams. Journal of Computer-Mediated Communication, 3(4), 0-0.

Ki, E., \& Hon, L. (2009). A measure of relationship cultivation strategies. Journal of Public Relations Research, $21(1), 1-24$.

Ki, E. J., \& Hon, L. (2009). Causal linkages between relationship cultivation strategies and relationship quality outcomes. International Journal of Strategic Communication, 3(4), 242-263.

Kotter, J. (2008). A sense of urgency. Boston, MA: Harvard Business Press.

Knox, J. (2007). Visual-verbal communication on online newspaper home pages. Visual communication, 6(1), $19-53$.

Krajicek, J. (2008). Effective communication is "hitched to everything in the (business) universe." Business Communication Quarterly, 71(3), 369-373. 
Lam, S., \& Ho Kin, F. (2010). Personal development empowerment through ICT in corporate learning: A case study of two developing cities in China. International Journal of Advanced Corporate Learning, 3(2), 14-20.

Le Roux, L., \& Oosthuizen, H. (2010). The development of an instructional design model as a strategic enabler for sustainable competitive advantage. South African Journal of Business Management, 41 (1), 25.

Lentzos, F., \& Rose, N. (2009). Governing insecurity: contingency planning, protection, resilience. Economy and Society, 38(2), 230-254.

Lewis, L. K. (1999). Disseminating information and soliciting input during planned organizational change: Implementers' targets, sources, and channels for communicating. Management Communication Quarterly, 13(1), 43-75.

Liu, L., Chua, C., \& Stahl, G. (2010). Quality of communication experience: Definition, measurement, and implications for intercultural negotiations. Journal of Applied Psychology, 95(3), 469-487.

Mamatoglu, N. (2008). Effects on organizational context (culture and climate) from implementing a 360degree feedback system: The case of Arcelik. European Journal of Work \& Organizational Psychology, 17(4), 426-449.

Manoj, B., \& Baker, A. (2007). Communication challenges in emergency response. Communications of the ACM, 50(3), 51-53.

McNeish, J., \& Mann, I. (2010). Knowledge sharing and trust in organizations. IUP Journal of Knowledge Management, 8(1/2), 18-38.

Newsom, D., Turk, J., \& Kruckeberg, D. (2012). Cengage Advantage Books: This is PR: The Realities of Public Relations. Cengage Learning.

Ogrean, C., Herciu, M., \& Belascu, L. (2009). Searching for sustainable competitive advantage-- From tangibles to intangibles. Journal of US-China Public Administration, 6(4), 1-9.

Onnela, J. P., Saramäki, J., Hyvönen, J., Szabó, G., Lazer, D., Kaski, K., ... \& Barabási, A. L. (2007). Structure and tie strengths in mobile communication networks. Proceedings of the national academy of sciences, 104(18), 7332-7336.

Payne, L. (2006). Synthesizing crisis communication and reputation management: An experimental examination of memory. Journal of Promotion Management, 12(3/4), 161-187.

Piccoli, G., \& Ives, B. (2005). IT-Dependent strategic initiatives and sustained competitive advantage: A review and synthesis of the literature. MIS Quarterly, 29(4), 747-776

Poyatos, F. (Ed.). (1992). Advances in Non-Verbal Communication: Sociocultural, clinical, esthetic and literary perspectives. John Benjamins Publishing Company.

Raman, P., Wittmann, C., \& Rauseo, N. (2006). Leveraging CRM for sales: The role of organizational capabilities in successful CRM implementation. Journal of Personal Selling \& Sales Management, 26(1), $39-53$.

Riechmann, T., \& Weimann, J. (2008). Competition as a coordination device: Experimental evidence from a minimum effort coordination game. European Journal of Political Economy, 24, 437-454.

Sethi, D., \& Seth, M. (2009). Interpersonal communication: Lifeblood of an organization. IUP Journal of Soft Skills, 3(3/4), 32-40.

Sissell, K. (2012). BP sells Texas City refinery to Marathon for $\$ 2.5$ billion. Chemical Week, 174(26).

Snow, N., (2010). BP working to rebuild its trust as it responds to spill. Gas and Oil Journal. Retrieved from http://www.ogj.com/index/article-display/2514633995/articles/oil-gas-journal/general-interest2/companies/2010/06/bp-working to rebuild.html

Subapriya, K. (2009). The importance of non-verbal cues. ICFAI Journal of Soft Skills, 3(2), 37-42.

Tarokh, V., Seshadri, N., \& Calderbank, A. R. (1998). Space-time codes for high data rate wireless communication: Performance criterion and code construction. IEEE transactions on information theory, 44(2), 744-765. 
Tepper, B., Moss, S., Lockhart, D., \& Carr, J. (2007). Abusive supervision, upward maintenance communication, and subordinate's psychological distress. Academy of Management Journal, 50(5), 11691180.

Wood, A. (2009). Speaking my language? Journal of Financial Services Marketing, 14(1), 92-97.

Tucker, M. L., Meyer, G. D., \& Westerman, J. W. (1996). Organizational communication: Development of internal strategic competitive advantage. The Journal of Business Communication (1973), 33(1), 51-69.

Yin, Robert (1989) Case Study Research: Design and Methods, Applied Social Research Methods Series, Volume 5, Sage Publications: Newbury Park. 